\title{
PENGARUH KUALITAS JASA SERVIS DAN KEPUASAN KONSUMEN TERHADAP LOYALITAS KONSUMEN PADA TOKO ASUS GLOBAL STORE DI DENPASAR
}

\author{
Ni Luh Indiani ${ }^{1}$ \\ Anak Agung Elik Astari² \\ Program Studi Manajemen, Fakultas Ekonomi, \\ Universitas Mahendradatta Bali \\ Jl. Ken Arok No. 12 Peguyangan Denpasar Utara, Bali 80115
}

\begin{abstract}
Abstrak
Penelitian ini bertujuan untuk menganalisis sejauh mana pengaruh Kualitas Jasa Servis (X1) dan Kepuasan Konsumen (X2) terhadap Loyalitas Konsumen (Y) pada toko Asus Global Store di Denpasar. Metode analisis yang digunakan pada penelitian ini adalah penelitian deskriptif dengan pendekatan kuantitatif dengan metode analisis regresi, adapun tahap-tahap pengujiannya adalah validitas, reliabilitas, asumsi klasik, analisis regresi linier berganda, koefisien determinasi dan pengujian hipotesis. Hasil pengujian hipotesis secara simultan menunjukkan pengaruh kedua variabel independen yang diteliti terbukti secara signifikan mempengaruhi variabel dependen Loyalitas konsumen. Hasil ini mengindikasikan bahwa naik turunnya loyalitas konsumen pada Asus Global Store di Denpasar tergantung oleh naik turunnya tingkat kualitas jasa servis dan kepuasan konsumen yang diberikan oleh usaha tersebut. Angka Adjusted $R$ Square sebesar 0,277 menunjukan bahwa $28 \%$ variasi Loyalitas Pelanggan dapat dijelaskan oleh kedua variabel independen dalam persamaan regresi. Sedangkan sisanya sebesar $72 \%$ dijelaskan oleh variabel lain diluar kedua variabel yang digunakan dalam penelitian ini.
\end{abstract}

Kata Kunci : kualitas jasa servis, kepuasan konsumen, loyalitas konsumen

\section{Pendahuluan}

Tuntutan pelanggan yang semakin meningkat akan layanan yang baik dan produk yang bermutu membuat para pengusaha dituntut untuk selalu mengevaluasi pelayanan. Di Denpasar sendiri toko komputer kini dapat dengan mudah ditemui, Persaingan akan menjadi semakin pesat karena adanya jenis usaha bisnis yang sama. Menghadapi pasar yang 
seperti ini perusahaan harus meningkatkan keunggulan bersaing (competitive advantage) yang dimiliki kalau mau tetap bertahan dalam persaingan industri. Kualitas pelayanan menjadi salah satu kunci utama keberhasilan. Dengan adanya kualitas pelayanan yang baik tentunya akan mempengaruhi rasa kepuasan konsumen. Dengan kualitas yang baik akan mendorong konsumen untuk menjalin hubungan baik dengan perusahaan.

Asus Global Store merupakan usaha perorangan yang bergerak dibidang jasa servis dan menjual berbagai macam produk seperti notebook, netbook, PC built up, PC rakitan, aksesoris laptop dan lainnya, berlokasi di jalan Teuku Umar Denpasar. Sesungguhnya setiap pengusaha mengharapkan untuk dapat terus meningkatkan jumlah konsumennya, dan selanjutnya berupaya untuk mempertahankannya sepanjang masa. Begitu juga dengan toko Asus Global Store yang juga terus berusaha untuk mempertahankan loyalitas konsumen dengan memberikan kualitas pelayanan yang sesuai dengan harapan konsumen.

\section{Kerangka Dasar Teori}

\section{Kualitas Jasa Servis}

Menurut Assegaff (2009) dalam Mahanani (2010), definisi kualitas jasa adalah ukuran sejauh mana suatu pelayanan yang diberikan dapat memenuhi harapan konsumen. Pernyataan ini dipertegas oleh Tjiptono dalam Putriandari (2010), yang mengatakan bahwa kualitas jasa adalah tingkat keunggulan yang diharapkan dan pengendalian atas tingkat keunggulan tersebut untuk memenuhi keinginan konsumen.

\section{Kepuasan Konsumen}

Kepuasan konsumen dapat menjadi dasar menuju terwujudnya konsumen yang loyal atau setia. Kotrel (1997) dalam Pratiwi (2010) mengemukakan bahwa kepuasan konsumen adalah tingkat perasaan seseorang setelah membandingkan kinerja atau hasil yang dirasakan dibandingkan dengan harapan. Kepuasan didefinisikan sebagai persaaan senang atau kecewa seseorang dari membandingkan kinerja produk yang dirasakan dalam hubungan dan harapannya. Menurut pendapat Kotler yang lain mengenai kepuasan, merupakan fungsi dari kinerja yang dirasakan (perceived performance) dan harapan (expectations).

\section{Loyalitas Konsumen}

Loyalitas konsumen memiliki peran penting dalam sebuah usaha, mempertahankan konsumen berarti meningkatkan kinerja keuangan dan mempertahankan kelangsungan hidup suatu usaha, hal ini menjadi alasan utama bagi sebuah usaha untuk menarik dan mempertahankan konsumen. Griffin dalam Putriandari (2010), berpendapat bahwa konsumen yang loyal adalah konsumen yang sangat puas dengan produk atau jasa tertentu sehingga mempunyai antusiasme untuk memperkenalkan kepada siapapun yang dikenal.

\section{Metode Penelitian}

Penelitian ini menggunakan tipe penelitian deskriptif dengan 
pendekatan kuantitatif. Metode penelitian kuantitatif, sebagaimana dikemukakan oleh Sugiono (2012), yaitu metode penelitian yang berlandaskan pada filsafat positivisme, digunakan untuk meneliti pada populasi atau sampel tertentu, pengumpulan data menggunakan intrumen penelitian, analisis data bersifat kuantitatif/ statistik, dengan tujuan untuk menguji hipotesis yang ditetapkan.

Populasi dalam penelitian ini adalah konsumen Toko Asus Global Store yang berdomisili dikota Denpasar sebanyak 75 responden. Teknik pengambilan sampel menggunakan teknik purposive sampling, yaitu penentuan sampel dengan pertimbangan tertentu yaitu konsumen yang berkunjung pada toko Asus Global Store di Denpasar untuk melakukan servis maupun berbelanja kebutuhan pendukung komputer.

Teknik analisa data yang digunakan adalah analisis linier berganda dengan rumus :

$$
\mathrm{Y}=\mathrm{a}+b_{1+} x_{1}+b_{2+} x_{2}+\mathrm{e}
$$

Keterangan :

$$
\mathrm{Y}=\text { loyalitas konsumen }
$$

$\mathrm{a}=$ bilangan konstanta

$\mathrm{b}=$ bilangan koefisien

$x_{1}=$ kualitas jasa servis

$x_{2}=$ kepuasan konsumen

$\mathrm{e}=$ error/variabel pengganggu

Sebelum data dianalisis dilakukan uji validitas dan uji reliabilitas serta uji asumsi klasik.

\section{Hasil Penelitian}

\section{Uji Validitas dan Uji Reliabilitas}

Hasil uji validitas menunjukan bahwa seluruh koefisien kolerasi dari 23 indikator dengan 75 orang responden memiliki nilai lebih besar dari 0,2 maka dari itu dapat disimpulkan seluruh indikator pada penelitian ini dinyatakan valid.

Hasil perhitungan reliabilitas antara variabel kualitas jasa servis $\left(\mathrm{X}_{1}\right)$, kepuasan konsumen $\left(\mathrm{X}_{2}\right)$, dan loyalitas konsumen (Y), memperoleh koefisien Cronbach's Alpha lebih besar dari 0,6. Dengan demikian, maka hasil uji reabilitas terhadap keseluruhan variabel dinyatakan reliable.

\begin{tabular}{|c|c|c|c|c|c|c|c|c|c|c|}
\hline \multirow[b]{2}{*}{ Model } & \multirow[b]{2}{*}{$\mathrm{R}$} & \multirow[b]{2}{*}{$\begin{array}{c}\mathrm{R} \\
\text { Square }\end{array}$} & \multirow[b]{2}{*}{$\begin{array}{c}\text { Adjusted R } \\
\text { Square }\end{array}$} & \multirow{2}{*}{$\begin{array}{c}\text { Std. Error } \\
\text { of the } \\
\text { Estimate }\end{array}$} & \multicolumn{5}{|c|}{ Change Statistics } & \multirow[b]{2}{*}{$\begin{array}{l}\text { Durbin- } \\
\text { Watson }\end{array}$} \\
\hline & & & & & $\begin{array}{c}\text { R Square } \\
\text { Change }\end{array}$ & F Change & df1 & df2 & $\begin{array}{c}\text { Sig. } F \\
\text { Change }\end{array}$ & \\
\hline 1 & $.527^{a}$ & .277 & .257 & 1,731 & .277 & 13,826 & 2 & 72 & .000 & 1,970 \\
\hline
\end{tabular}

Model Summary ${ }^{b}$
a. Predictors: (Constant), X1,X2
b. Dependent Variable: $Y$ 
Berdasarkan tabel di atas dapat diketahui nilai Durbin watson sebesar 1,970. Sehingga nilai DW berada diantara dU $(1,680)<\mathrm{DW}($ $1,970)<4-\mathrm{dU}(4-1,680=2,3198$ ). Maka dapat disimpulkan bahwa dalam penelitian ini tidak terdapat autokorelasi. Artinya bahwa variabel independent dalam penelitian ini tidak terganggu atau terpengaruhi oleh variabel penggangu.

Berdasarkan hasil pengujiannya diperoleh kesimpulan bahwa Nilai koefisien determinasi $\left(\mathrm{R}^{2}\right)$ didapat besarnya pengaruh variabel bebas terhadap variabel terikat dalam penelitian ini adalah 0,277 atau $28 \%$. Sedangkan sisanya yaitu $72 \%$ dipengaruhi oleh variabel lain di luar variabel yang diteliti yang tidak dimasukkan dalam model penelitian ini.

Berdasarkan perhitungan pada tabel di atas diketahui nilai Sig. $F_{\text {hitung }}$ $0,000<$ alpha $(\alpha)$ 0,05 dengan demikian menunjukkan bahwa variabel kualitas jasa service $\left(\mathrm{X}_{1}\right)$, kepuasan konsumen $\left(\mathrm{X}_{2}\right)$, secara bersama - sama (simultan) mempunyai pengaruh yang signifikan terhadap loyalitas konsumen (Y).

\begin{tabular}{|c|c|c|c|c|c|c|}
\hline \multirow{2}{*}{\multicolumn{2}{|c|}{ Model }} & \multicolumn{2}{|c|}{$\begin{array}{l}\text { Unstandardized } \\
\text { Coefficients }\end{array}$} & \multirow{2}{*}{$\begin{array}{c}\begin{array}{c}\text { Standardized } \\
\text { Coefficients }\end{array} \\
\text { Beta }\end{array}$} & \multirow[b]{2}{*}{$t$} & \multirow[b]{2}{*}{ Sig. } \\
\hline & & B & Std. Error & & & \\
\hline \multirow[t]{3}{*}{1} & (Constant) & 10.318 & 2.452 & & 4,208 & .000 \\
\hline & $\mathrm{X} 1$ & .061 & .128 & .059 & ,479 & .633 \\
\hline & $\mathrm{x} 2$ & .471 & .118 & .491 & 3.994 & .000 \\
\hline
\end{tabular}

a. Dependent Variable: $Y$ 
Berdasarkan hasil perhitungan pada tabel di atas dapat dijelaskan pengaruh antara variabel variabel kualitas jasa service $\left(\mathrm{X}_{1}\right)$, kepuasan konsumen $\left(\mathrm{X}_{2}\right)$ terhadap loyalitas konsumen(Y) adalah sebagai berikut:

1) Variabel kualitas jasa service $\left(X_{1}\right)$ Nilai Sig. $t_{\text {hitung }}$ menunjukkan bahwa variabel kualitas jasa servis $\left(\mathrm{X}_{1}\right)$ sebesar $0,633>\alpha 0,05$. Artinya, variabel kualitas jasa service $\left(\mathrm{X}_{1}\right)$ secara parsial tidak berpengaruh signifikan terhadap loyalitas konsumen (Y).

2) Variabel kepuasan konsumen $\left(X_{2}\right)$ Nilai Sig. $t_{\text {hitung menunjukkan }}$ bahwa variabel kepuasan konsumen $\left(\mathrm{X}_{2}\right)$ sebesar $0,000<\alpha 0,05$. Artinya, variabel kepuasan konsumen $\left(\mathrm{X}_{2}\right)$ secara parsial berpengaruh signifikan terhadap loyalitas konsumen (Y).

Pada tabel (Uji t) menunjukkan bahwa variabel kepuasan konsumen $\left(\mathrm{X}_{2}\right)$ memiliki nilai koefisien regresi baku tertinggi yaitu sebesar 0,491 yang berarti bahwa variabel kepuasan konsumen merupakan variabel yang berpengaruh dominan terhadap loyalitas konsumen (Y) pada toko Asus Global Store.

\section{Pembahasan}

Pengaruh Kualitas Jasa Servis dan Kepuasan Konsumen Secara Simultan Terhadap Loyalitas Konsumen

Berdasarkan hasil penelitian menunjukkan bahwa variabel kualitas jasa servis dan kepuasan konsumen secara bersama - sama (simultan) berpengaruh signifikan terhadap loyalitas konsumen pada toko Asus Global Store di Denpasar. Hal ini dapat dibuktikan dengan hasil nilai signifikasi Fhitung sebesar $(0,00)<\alpha(0,05)$. hasil penelitian ini sejalan dengan hasil penelitian Mahanani (2010), Pratiwi (2011), Sinaga (2010) dan Fibrianto (2011) yang menyatakan bahwa secara simultan model yang digunakan dalam penelitian memiliki pengaruh signifikan terhadap loyalitas konsumen.

Berdasarkan kuesioner yang telah disebar, dibuktikan terdapat 54 responden dari 75 sampel yang melakukan kunjungan lebih dari 3x yang artinya lebih banyak konsumen yang mempercayakan perbaikan laptop / PC dan berbelanja kebutuhan komputer/ PC pada toko Asus Global Store di Denpasar. Konsumen yang berulang kali datang tidak hanya untuk servis Laptop/ PC ataupun membeli kebutuhan pendukung laptop/ PC mereka, melainkan sebagian dari mereka membawa calon konsumen baru. Kepuasan yang mereka rasakan membuat para konsumen ini ingin selalu merekomendasikan toko Asus Global Store. Karena sesungguhnya setiap sebuah usaha pastinya ingin selalu menambah jumlah konsumennya agar mampu menambahkan keuntungan bagi usaha itu sendiri.

Hal ini sejalan dengan Sinaga (2010) yang mengemukakan bahwa konsumen akan selalu melakukan proses evaluasi alternatif pasca konsumsi. Hasil dari pasca konsumsi adalah konsumen merasa puas (statisfaction) atau tidak puas (dissatisfaction) terhadap konsumsi produk atau jasa yang telah dilakukan. Konsumen yang antusias terhadap toko Asus Global Store yang berkunjung lebih dari 3x, tidak lagi mempertimbangkan 
faktor-faktor yang berpengaruh dalam penentuan pilihan, karena telah tertanam dalam diri mereka bahwa jasa servis dan pendukung kebutuhan laptop/ PC yang dibeli sesuai dengan harapan dan kebutuhan para konsumen.

Menurut Hurriyati (2010) kualitas pelayanan memiliki hubungan yang erat dengan kepuasan konsumen. Kualitas jasa memberikan suatu dorongan kepada konsumen untuk menjalin ikatan hubungan yang kuat dengan perusahaan. Dalam jangka panjang, ikatan seperti ini memungkinkan pengusaha untuk memahami dengan seksama harapan konsumen serta kebutuhan mereka. Hal ini sejalan dengan Sinaga (2010) yang mengemukakan imbalan dari loyalitas sendiri bersifat jangka panjang dan kumulatif, jadi semakin lama seseorang pelanggan loyal terhadap suatu produk/ jasa, semakin besar laba yang diperoleh perusahaan dari seorang calon konsumen. Dengan demikian, toko Asus Global Store dapat meningkatkan kepuasan konsumen di mana pengusaha memaksimumkan pengalaman konsumen yang menyenangkan dan meminimumkan pengalaman konsumen yang kurang menyenangkan.

Pengaruh Kualitas Jasa Servis dan

Kepuasan Konsumen Secara Parsial

Terhadap Loyalitas Konsumen Pada

Toko Asus Global Store di Denpasar.

1. Pengaruh Kualitas Jasa Servis secara Parsial Terhadap Loyalitas Konsumen

Ni Luh Indiani

Anak Agung Elik Astari
Menurut hasil penelitian Mahananni (2010), kualitas jasa adalah ukuran sejauh mana suatu pelayanan yang diberikan dapat memenuhi harapan konsumen. Namun, fakta penelitian di lapangan berdasarkan dari hasil wawancara dan observasi menyatakan bahwa kualitas jasa servis tidak berpengaruh signifikan terhadap loyalitas konsumen pada toko Asus Global Store di Denpasar. Kualitas jasa servis tidak mempunyai pengaruh yang signifikan terhadap loyalitas konsumen. Hal ini sejalan dengan penelitian dari Saputra (2013) bahwa jasa servis tidak serta merta akan membuat pelanggan loyal terhadap jasa/ produk yang ditawarkan.

Berikut indikator dari kualitas jasa servis yang tidak mempengaruhi loyalitas konsumen:

a. Keandalan (reliability) kemampuan karyawan toko Asus Global Store dalam memperbaiki printer/ PC yang mengalami masalah. Walaupun dukungan keandalan semakin baik maka tidak akan mempengaruhi loyalitas konsumen pada toko Asus Global Store.

b. Daya tanggap (responsiveness) kecepatan dan kesigapan, karyawan Asus Global Store dalam menyelesaikan atupun merespon masalah, dan memberikan pelayanan serta tanggap. Semakin ditingkatkannya daya tanggap pada toko Asus Global Store maka tidak akan meningkatkan loyalitas konsumen pada toko Asus Global Store.

c. Jaminan (assurance) toko Asus Global Store selalu memberikan 
garansi untuk setiap perbaikan hardware (perangkat keras) laptop/ PC. Apabila pembeli tidak puas atau jika jasa tidak sesuai dengan yang diperjanjikan dalam masa tertentu maka karyawan toko Asus Global Store setuju untuk memperbaiki dengan mengganti item atau bagian yang rusak. Opsi yang diberikan oleh penyedia terhadap tidak tercapainya kualitas barang akibat kerusakan salah satu bagian barang adalah hanya penggantian bagian yang rusak saja. Ketika jaminan dalam perbaikan laptop/ PC dilakukan maka tidak akan meningkatkan loyalitas konsumen pada toko Asus Global Store.

d. Empati (emphaty) kemudahan karyawan Asus Global Store dalam memberikan perhatian yang tulus dan bersifat individual atau pribadi yang diberikan kepada para konsumen dengan berupaya memahami keinginan konsumen. Di mana suatu toko diharapkan memiliki pengertian dan pengetahuan tentang pelanggan, memahami kebutuhan pelanggan secara spesifik, serta memiliki, waktu pengoperasian yang nyaman bagi pelanggan. Ketika kemudahan dalam melakukan hubungan, komunikasi yang baik, perhatian pribadi, dan memahami kebutuhan para konsumen dilakukan maka tidak akan meningkatkan loyalitas konsumen pada toko Asus Global Store.

e. Bukti fisik (tangibles) fasilitas fisik yang ditawarkan kepada konsumen Asus Global Store yang meliputi fisik, perlengkapan, pegawai dan saran komunikasi. Ada atau tidak adanya dukungan bukti maka tidak akan mempengaruhi peningkatkan loyalitas konsumen pada toko Asus Global Store.

Dapat disimpulkan bahwa keandalan (reliability), daya tanggap (responsiveness), jaminan (assurance), empati (emphaty) dan bukti langsung (tangibles) tidak berpengaruh bagi konsumen pada toko Asus Global Store di Denpasar. Tanpa adanya kualitas pelayanan yang baik tentunya tidak akan mempengaruhi rasa loyalitas konsumen. Bahkan semakin meningkatnya kualitas jasa servis pada toko Asus Global Store tidak akan memberikan dampak dalam meningkatkan loyalitas konsumen pada toko Asus Global Store di Denpasar.

2. Pengaruh Kepuasan Konsumen secara Parsial Terhadap Loyalitas Konsumen

\begin{tabular}{llr}
\multicolumn{2}{c}{ Kepuasan } & \multicolumn{1}{c}{$\begin{array}{c}\text { konsumen } \\
\text { secara }\end{array}$} \\
parsial memiliki & pengaruh & yang \\
signifikan terhadap loyalitas & konsumen. \\
Berdasarkan & analisis & regresi \\
menunjukkan & bahwa & kepuasan
\end{tabular}
konsumen berpengaruh positif terhadap loyalitas konsumen. Jika kepuasan konsumen meningkat maka loyalitas konsumen akan meningkat, begitu pula sebaliknya jika kepuasan konsumen menurun maka loyalitas konsumen akan menurun. Berdasarkan hasil penelitian ini menunjukkan ada pengaruh yang positif dan signifikan antara variabel kepuasan konsumen terhadap variabel loyalitas konsumen. Hal ini disebabkan kepuasan konsumen Toko Asus Global Store di Denpasar telah terpenuhi, karena konsumen Toko Asus Global Store di 
Denpasar merasa puas dengan pelayanan yang diberikan, karena persepsi mereka terhadap layanan yang diberikan telah sesuai dengan harapan. Apabila kepuasan konsumen terpenuhi maka manfaat kepuasan konsumen akan tercapai yaitu terciptanya loyalitas konsumen pada toko Asus Global Store di Denpasar.

Hasil penelitian di atas diperoleh dari hasil penilaian responden setelah menggunakan jasa servis maupun membeli aksesoris pendukung laptop/ PC pada Toko Asus Global Store di Denpasar. Hal ini sejalan dengan pendapat Pratiwi (2011) mengemukakan bahwa kepuasan konsumen adalah tingkat perasaan seseorang setelah membandingkan kinerja atau hasil yang dirasakan dibandingkan dengan harapan. Jadi seseorang konsumen akan bisa mengatakan puas atau tidak setelah menggunakan atau mengosumsi jasa servis maupun aksesoris pendukung laptop/ PC dan membandingkan antara harapan dan persepsi mereka atas pelayanan yang diterima. Menurut Hurriyati (2010) apabila harapan konsumen terpenuhi maka akan menciptakan kepuasan yang tinggi karena telah menciptakan kesenangan konsumen yang akan berpengaruh pada pola perilaku selanjutnya yang menciptakan loyalitas konsumen.

Berikut ini adalah faktor - faktor

yang mampu mempengaruhi kepuasan

konsumen sehingga dapat membentuk

loyalitas konsumen :

a. Asus Global Store mengutamakan kualitas produk seperti aksesoris pendukung laptop yakni flashdisk, mouse, keyboard exsternal, speaker dan lain - lain. Tidak dapat dipungkiri bahwa kualitas produk menjadi syarat utama bagi pelaku bisnis sebagai cara meningkatkan penjualan produk. Dengan produk yang berkualitas baik maka pelaku bisnis tidak perlu menunggu dalam waktu lama untuk mendatangkan banyak konsumen.

b. Menetapkan harga yang relatif murah merupakan daya tarik tersendiri bagi Asus Global Store di Denpasar. Salah satu cara untuk memenangkan persaingan pasar atau merebut hati konsumen agar membeli yaitu dengan menjual barang dengan harga yang lebih murah dari harga yang ada di pasaran, sebab konsumen sangat menyukai harga pembelian dari suatu barang yang lebih murah dari yang lainnya, walaupun perbedaan harga yang diberikan oleh toko hanya berbeda Rp 2.000,- atau di bawah dari itu (kecil nilainya).

c. Memberikan pelayanan yang memuaskan pada semua konsumen. Pada dasarnya semua konsumen adalah sama, berapa pun uang yang mereka keluarkan dan berapa pun produk yang mereka beli, mereka tetap mempunyai hak yang sama untuk mendapatkan pelayanan terbaik. Jika pelanggan mendapatkan pelayanan yang memuaskan saat membeli produk di toko Asus Global Store maka mereka tidak akan sungkan untuk datang lagi dan membeli dalam jumlah yang lebih besar.

d. Menciptakan kesan positif atau emosional. Kesan positif yang 
terekam di benak konsumen sehingga toko Asus Global Store akan selalu diingat. Hal sederhana yang bisa dilakukan misalnya adalah dengan memberikan senyum/ salam yang ramah, menjaga tutur bahasa, mau mendengarkan dan membantu mereka dengan tulus serta cepat tanggap. Dengan demikian mereka akan menceritakan 'kebaikan' toko Asus Global Store kepada orangorang terdekatnya sehingga akan menciptakan loyalitas konsumen.

e. Faktor yang terakhir ialah faktor kemudahan, salah satu faktor penentu kesuksesan roda usaha adalah lokasi yang tepat. Lokasi usaha yang strategis akan sangat mempengaruhi produk atau jasa yang ditawarkan, menentukan laku/tidaknya suatu produk. Terciptanya kepuasan pelanggan sendiri membuat konsumen Asus Global Store menjadi semakin setia dan ingin terus menggunakan jasa servis ataupun berbelanja kebutuhan laptop/ PC mereka. Loyalitas ini terlihat dari kesetiaan konsumen yang menggunakan jasa servis ataupun berbelanja kebutuhan laptop/ PC baik untuk keperluan sendiri maupun sebagai perantara bagi keperluan pihak lain untuk terus berlangganan pada toko Asus Global Store dalam jangka panjang dengan cara menggunakan jasa servis ataupun berbelanja kebutuhan laptop/ PC secara berulang-ulang dengan suka rela merekomendasikan produk dan jasa pada toko Asus Global Store di Denpasar kepada rekan-rekannya.

\section{Penutup}

Terdapat pengaruh yang signifikan antara variabel kualitas jasa servis dan kepuasan konsumen terhadap variabel loyalitas konsumen secara bersamasama pada toko Asus Global Store di Denpasar. Dari dua variabel independen yaitu kualitas jasa servis dan kepuasan konsumen yang berpengaruh signifikan secara parsial terhadap loyalitas konsumen adalah variabel kepuasan konsumen. Sedangkan variabel kualitas jasa servis secara parsial tidak berpengaruh signifikan terhadap loyalitas konsumen pada toko Asus Global Store di Denpasar.Variabel kepuasan konsumen merupakan variabel yang paling berpengaruh terhadap loyalitas konsumen pada toko Asus Global Store di Denpasar.

Saran yang bisa diberikan kepada toko Asus Global Store di Denpasar agar Pihak Asus Global Store harus lebih memperhatikan keluhan - keluhan yang disampaikan konsumennya, dan tidak mengacuhkan keluhan - keluhan tersebut dengan cara menyediakan kotak saran, menyediakan kartu komentar, dan lain sebagainya. Informasi ini dapat memberikan ide - ide dan masukan kepada toko Asus Global Store dan mencoba untuk sebaik mungkin untuk menanggulanginya dengan cepat dan cepat. Toko Asus Global Store juga sebaiknya terus meningkatkan kepuasan konsumen dengan cara meningkatkan kualitas produk, meningkatkan kualitas pelayanan, terus menciptakan kesan positif atau emosional, baik sebelum maupun sesudah terjadinya transaksi. Agar para konsumen menjadi semakin puas dan loyal terhadap toko Asus Global Store, dan tidak segan untuk 
mereferensikan toko Asus Global Store kepada para koleganya. Toko Asus Global Store juga sebaiknya senantiasa memperhatikan dan menjaga hubungan baik dengan para konsumennya, misalnya memberikan pelayanan khusus bagi konsumen yang sudah lama, serta selalu menjaga komunikasi dan interaksi secara aktif dengan para konsumen, sehingga para konsumen tidak akan merasa asing

\section{Daftar Pustaka}

\section{Buku :}

Amalia, Siti (2011)."Alat Analisis Data Aplikasi Statistik Untuk Penelitian Bidang Ekonomi \& Sosial”. Yogyakarta.

Freddy, Rangkuti (2006). "Teknik Mengukur dan Strategi Meningkatkan Kepuasan Pelanggan". Jakarta : Penerbit PT Gramedia Pustaka Utama

Ghozali, Imam (2012). "Aplikasi Multivariate Dengan Program IBM SPSS 19". Universitas Diponegoro, Semarang.

Kotler, Philip Dan Kevin Lane Keller (2012). “Manajemen Pemasaran”. Edisi Kedua Belas. Indeks, Jakarta.

Priyatno, Duwi (2013). “Analisis Korelasi, Regresi dan Multivariate dengan SPSS”. Gava Media, Yogyakarta

Sugiyono (2012) . "metode penelitian kuantitatif, kualitatif dan $R \& D$ ”. Bandung : Alfabeta.

\section{Skripsi :}

Mahanani, Sonya (2010). “Analisis pengaruh kualitas pelayannan terhadap kepuasan pelanggan dala pembayaran rekening listrik (studi pada unit pelayanan pelanggan Semarang barat)". Universitas Diponegoro, Semarang.

Putriandari, Aulia Siwi (2011).”Analisis pengaruh kualitas jasa dan kepuasan pelanggan terhadap loyalitas pelanggan pengguna Telkom Speedy di Semarang”. Universitas Diponegoro, Semarang.

Pratiwi, Dinar Ika (2010)."Analisis pengaruh harapan pelanggan, kualitas produk, kepuasan pelanggan terhadap loyalitas pelanggan internet flash unlimited di Semarang". Universitas Diponegoro, Semarang.

Sasongko, Ferdian Ario (2012). "Analisis pengaruh motivasi konsumen, persepsi kualitas, dan sikap konsumen terhadap keputusan pembelian PC Tablet iPad". Universitas Diponegoro, Semarang.

Sinaga, Partua Pramana Hamongan (2010)."analisis pengaruh kualitas pelayanan, kepuasan pelanggan, dan lokasi terhadap loyalitas pelanggan (studi kasus pada warnet chamber Semarang)". Universitas Diponegoro, Semarang.

Jurnal :

Evanchitzky, Heiner, Ramaseshan B, Woisetschlager. M.David, Richelsen Verena, Blut Markus, Backhaus Cristof (2007)."Consequences Of Customer Loyality To The Loyality Program and To The Company. Jurnal Academy of Marketing Science. 
Rahcmawati, Rina (2010)."Pengaruh kepuasan terhadap loyalitas pelanggan (sebuah kajian terhadap bisnis makanan)"

Saputra, Falla Ilhami (2013). “Kualitas

Layanan, Citra dan Pengaruhnya terhadap Loyalitas melalui Kepuasan

Pelanggan (Studi Pada PT Bank Bni 46

Sentra Kredit Kecil Surabaya)".

Universitas Brawijaya Malang 